\title{
Variables predicting prospective biology teachers' acceptance perceptions regarding gene technology
}

\author{
Mirac Yilmaz ${ }^{1 *}$, Haydar Demirhan ${ }^{2}$ \\ $1^{*}$ Department of Science and Mathematics Fields in Secondary Education, Hacettepe University, Ankara, Turkey \\ ${ }^{2}$ Department of Statistics, Hacettepe University, Ankara, Turkey \\ For correspondence: yilmazmirac@gmail.com
}

\begin{abstract}
:
The different opinions on products and applications of gene technology (GT) draw attention to the training and education activities related to GT. The purpose of this study is to review some variables predicting the acceptance perception regarding GT, and to investigate their changes at levels. The prospective teachers' subjective knowledge and interest levels in relation to the use of GT and their risk and acceptance perceptions have been questioned through a Likert type questionnaire. Latent class and binary logistic regression analyses were used. This study was carried out with 135 prospective biology teachers. According to our study, it is possible to state that there are variables, at $5 \%$ level of significance, predicting acceptance of interest and risk variables in terms of GT. As perception towards GT being risky decreases and interest towards GT increases, the acceptance perception regarding GT increases.
\end{abstract}

Keywords: prospective biology teacher, gene technology, acceptance, latent class analysis, binary logistic regression analysis

\section{Introduction}

Gene technology (GT) applications bring new and effective solutions to the problems in various (health, environment, industry, etc.) areas. However today, the results these applications may bring up in relation to ethics, ecology, and health also cause reactions and arguments. The increasing participation and significance of the public taking place in these arguments have directed the attention to the formation process of their opinion and attitude (acceptance/rejection, risk-acceptance perception, ability to evaluate the benefits and dangers), therefore to the gaining information about GT and education activities on GT (Gaskell et al., 1998: Harms and Bayrhuber, 1999; Knox, 2000; Gaskel and Bauer, 2001; Harms, 2002; Dawson and Schibeci, 2003). The youth acquiring their knowledge on method and applications of GT in education institutions and by well-prepared curriculum and well-educated teachers, makes it obvious that it will provide qualitative evaluations on these matters. In this case, it is obvious that it is necessary to continue studying on GT education and teaching by beginning with the teacher education at first. When it is thought that the formation of qualitative learning environment is one of the most important responsibilities of the teachers and that the teachers' attitudes may have an influence on the students' attitudes (Harman and Akın, 2006; Šorgo and Ambrožič-Dolinšek, 2009), the importance of the development of prospective biology teachers' knowledge and judgement on GT can be understood.

Examining the learning environment that affects the formation of knowledge and opinions of the individuals during the knowledge acquisition process may demonstrate the efficiency of the school offering education in biology. In this sense, analyzing the biology teachers' subjective knowledge and interest perceptions on GT and studying risk and acceptance perceptions on GT issues might be a 
guide for predicting the quality of teaching related to GT and biotechnology to be taught in the coming years.

The purpose of this study is to examine the variables that presume their acceptance perception of GT (knowledge, interest, risk perception of GT, gender, having taken classes on GT), and to examine the changes among the levels of these variables of prospective biology teachers.

\section{Theoretical Background}

Some researches state that depending on the different products and applications of GT, the acceptance of individuals/consumers differs (Bonfadelli et al., 2002; Magnusson and Hursti Koivisto, 2002). Kliment and Renn (1993) put forward that generally in European countries the attitude of the public is sceptic and indecisive; whereas some researchers stress that this indecisive attitude is due to lack of knowledge (Pfister et al., 2000). Besides knowledge in the acceptance of GT, some studies state that views on trust, health, and naturality, different sociodemographic factors (gender, age, educational level, place of residence, etc.), and risk-benefit perceptions are effective (Pfister et al., 2000; Siegrist, 2000; Knox, 2000; Hursti et al., 2002; Magnusson and Koivisto-Hursti, 2002; Connor and Siegrist, 2010).

Many studies point out that the knowledge process and the evaluation of GT are closely interrelated, and that information may effect attitude and evaluations towards GT (Merten, 1999; Pfister et al., 2000; Jallinoja and Aros, 2000; Hornig-Priest et al., 2003; Costa-Font et al., 2008; Connor and Siegrist, 2010). This situation points out the importance of the knowledge process in researching acceptance judgments towards GT. Knowledge can be measured as either subjective knowledge, which is people's perceptions of how much they know, or as objective knowledge, which measures what people actually know (Urban and Pfenning, 1999; Connor and Siegrist, 2010), and it has been shown that subjective knowledge is clearly related to general attitudes (Costa-Font et al., 2008).

According to Urban and Pfenning (1999), interest, which can be defined as a cognitive preparation in sense of being deeply preoccupied with a material, is important in views of carefully considering information sources and thinking and evaluating the received information. The

Elaboration Likelihood Model, which was developed in the early 1980s by Petty and Cacioppo, is also worth the attention in order to understand interest through gaining knowledge on GT and acceptance behaviors. According to this model, people are interested in the experience and the message existing in their memory regarding the issue, they carefully review their experience and background, and if elaborated, they analyze the information, try to understand, and generate an interpretation. In other words, by carrying out their evaluations they gain knowledge and develop an attitude (Elpeze-Ergeç, 2004; Kağıtçıbaşı, 2005). This situation brings forward the thought that those interested in GT will want to gain more information on GT and review their experiences, therefore will be able to process and evaluate information more actively.

In addition, very few people have directly experienced GT applications and have come across with their effects and again very few people have had the chance to approach experts directly, all of which might differentiate opinions and evaluations on GT (Peters, 1999). Siegrist (2000) has stated in his research, in which he has determined that perceived risks and benefits significantly influence the acceptance of GT, that trust, on the other hand, has an indirect influence (by forming positive effects for perceived benefits and negative effects for perceived risks).

As both enactors and practitioners, and as users, what kind of attitude and acceptance perception we will have in respect of GT, which potentially includes many applications that affect our lives, is a matter of concern. When the influence of the information and attitudes the teachers transfer to their 
students is considered, assessing the instructors, who formally educate the society on GT, concerning their knowledge acceptance, attitude, and behaviors regarding GT also has a significant role. Therefore prospective teachers who will be biology teachers in the future were selected.

\section{Research Questions}

The problems which will be answered during this study are as follows:

- Are the acceptance perceptions of prospective biology teachers in relation to GT predicted through variables of their subjective knowledge on GT, their interest, risk perception, gender, and having attended classes on GT?

- What is the influence of an increase or a decrease in levels of variables predicting acceptance perception on GT of prospective biology teachers?

\section{Method}

Participant Sample

This study was carried out with 135 prospective biology teachers at the Department of Education of Biology, Faculty of Education. 21 (15.6\%) male and $114(84.4 \%)$ female, in total 135 students participated in this study from a typical public university in Turkey. Their ages ranged from 18 to 26 years. They were from various grades in faculty of education of the university, studying to become a biology teacher in the area of secondary education. Although some of them ( 82 of 135, 60.7\%) were experienced in their fields, none of them were directly related to biotechnology.

\section{Data Collection Tool}

The prospective teachers' subjective knowledge and interest levels in relation to the use of GT on human, animal, plants, and microorganisms and their risk and acceptance perceptions on issues of GT have been questioned through a Likert type questionnaire. While preparing the questionnaire, literature review on GT and other basic sources in related areas have been used (Todt and Götz, 1997; Todt and Götz, 1998; Brown, 2002). To evaluate the prospective teachers' subjective knowledge levels a 4 -level scale questionnaire with 4 items (1. The use of GT on humans, ... 2. The use of GT on animals, ... 3. The use of GT on microorganisms, ... 4. The use of GT on plants, ...), from "I know very well" to "I know very little"; to evaluate their interest levels a 4-level scale questionnaire with 4 items $(1 \ldots$ in GT applications on humans; 2. ... in GT applications on animals; 3. ... in GT applications on microorganisms; 4 . ... in GT applications on plants) from "I'm very interested" to "I'm not interested"; as regards their risk perception on matters of GT a 5-level scale questionnaire with 7 items $(1 . .$. that when animals bred in GT laboratories are set free anywhere in the world, they set risk for the ecologic balance; 2. ... that the administrative management will set risk in terms of designating the policy and laws in relation to GT and being insufficient at carrying them out 3.... that gene technologically food, whose structure has been genetically changed, set the risk of being dangerous to human health. 4 . ... that doing researches on humans' hereditary structure will set the risk of causing experiments in producing "human of certain genetic features". 5. ... that when plants produced in GT laboratories are set free anywhere in the world, they set risk for the ecologic balance. 6. ... that by dangerous microorganisms scattering from GT laboratories set the risk of thousands of lives in being danger. 7. ... that by bacterias used in environmental technology (getting rid of garbage, refining unclean water, and such) getting out of control would set the risk of them being of more harm than help.) from "I find it very unlikely" to "I find it very likely" to be risk; as regards their acceptance perception on matters of GT a 5-level questionnaire with 7 items (1. ... the analysis (Genom analysis) of human's genetic structure. 2. ... high cost substances (such as insulin, interferon) being of low cost than microorganisms altered with GT. 3. ... alteration of human embrio genes in order to prefent a hereditary disease. 4 .... the use of genetically altered plants and microorganisms to 
be used in protecting the environment (eg. Bioplastic production). 5. ... the genetic alteration of useful plants (such as grains) to increase efficiency. 6.... the genetic alteration of useful animals (such as cows, sheep) to increase efficiency. 7. ... the processing of GT in order to improve the taste and stability of food.), from "I definitely accept" to "I definitely do not accept" were prepared.

\section{Data Analysis}

In this study, by using PASW 18.00 and the R program, and the latent class analysis and binary logistic regression analyses have been carried out.

Latent class analysis is an analysis method used quite often in education sciences and social sciences. Latent class analysis can be accepted as equivalent to factor analysis of multivariate statistical methods. Following the developments in factor analysis used for quantitative variables, latent class analysis has been put forward due to the need of carrying out a similar analysis, especially in social sciences, for categorical variables as latent class analysis does not require strong assumptions like multivariate normality and continuity of variables, it is more flexible and useful than the factor analysis. By using manifest variables in latent class analysis, it is possible to deduce latent variables (Heinen, 1996; Demirhan, 2011). Bergan (1983) provides detailed information on latent class analysis and its use in education sciences. At the beginning of the latent class analysis, the number of classes of the latent variable is unknown. In order to determine the number of classes of the latent variable, analyses are carried out for various latent class numbers and the number of latent classes of the analysis that provides the smallest value of the Swarts Bayesian Criterion (SBC) to be used as the number of latent classes (Nylund et al., 2007). The number of latent classes of this study is determined in this sense and by using the equivalent latent class possibilities, observations have been assigned to newly generated variables. In order to carry out a latent class analysis, the "polytomous variable latent class analysis" procedure, provided by Linzer and Lewis (2011), in the R program has been used.

To investigate the relation among dependent and independent variables, regression models are used. The binary logistic regression proposed for binary answer variable modeling is used to put forward the relationship structure between binary categorical response variable and categorical or continuous explanatory variables (Cabrera, 1994). The binary logistic regression modeling requires obtaining fewer amounts of assumptions than the classical regression modeling. The multicollinearity problem, which leads to misleading in tests of significance among explanatory variables, should not exist. In order to evaluate the existence of the multicollinearity problem, the amount of binary relations among the explanatory variables should be considered. In addition, it should be checked whether all of the explanatory variables also provide the independence model or not. This control could be carried out with evaluation of the independence log-linear model, which implies that the variables are mutually independent from one another. This evaluation can be done by using the Mosaic Plots. Moreover, the existence of influential observations or outliers that lead to invalid parameter predicts should be evaluated through the plots of standardized residuals versus predicted values. Furthermore, from this plot, the threshold value, which will be used to assign future observation to the levels of latent variable, can be determined by a visual inspection. This threshold value is a probability value corresponding to the region where the gap is seen between dots in the plot of standardized residuals versus predicted values. In addition, instead of the coefficient of determination in the classical regression, in the logistic regression the Nagelkerke's coefficient of determination $\left(\mathrm{R}^{2}\right)$ that was developed for this analysis is used. In addition to the coefficient of determination, in evaluating the goodness of fit of the model, correct classification rates are used. For the model to be fit, the correct classification rates of dependent variable classes are expected to be around 70\% (Menard, 1995, Hosmer and Lemeshow, 1989). In this study, the binary logistic analysis was carried out by using the PASW 18.00 software. The approach of Hsieh and colleagues (1998) was used to evaluate the sample size to be used for the binary logistic regression analysis. 


\section{Results}

Formation of new knowledge, interest, risk, and acceptance variables regarding gene technology and preview for binary logistic regression

By using the latent class analysis in this study, new subjective knowledge, interest, risk, and acceptance variables were formed to state views on this matter of subjective knowledge, interest, risk, and acceptence items regarding GT.

Before the analysis, whether the present 135-unit sample size was enough or not was evaluated at first. For this evaluation, according to the approach provided by Hsieh et al. (1998), in the hypothesis tests to be carried out with the 135-unit sample, due to the possibility of 0.05 Type I error rate, it will be run with a power of around 0.75 . This power value has been evaluated as an appropriate value.

Between the risk and interest variables, there is a 0.35 relation in the opposite direction. From this sense, it is possible to state that the increase in the thought of GT being risky leads to decrease in interest. According to this, as the opinion on GT being risky increases interest to GT decreases.

Chi-square tests between the dependent acceptance variable and the independent variables were performed to gain preliminary information to figure out whether the independent variables have a significant effect on the acceptance variable.

It is likely to state that the acceptance variable and interest and knowledge variables have a significant relation at $5 \%$ level of significance when the acceptance and independent variables are considered binary, whereas the correlation coefficient calculated between the knowledge and acceptance variables is not significant. It is essential to be careful when modeling due to the P-value being close to 0.05 , significant results may be obtained by considering the variables as a group instead of binary. In further models, taking all of these variables into consideration might provide significant results.

Binary logistic regression regarding acceptance of gene technology

In the binary logistic regression analysis carried out to research whether the subjective knowledge, interest, risk, gender, and having taken a course variables predict the GT acceptance, a complete cluster analysis, in which all variables are in a model, was applied. In the analysis firstly, the "less interested" category of the interest variable, the "very risky" category of the risk variable, the "very knowledgable" category of the knowledge variable, and the "I accept" category of the interest variable were considered as the reference categories.

The variables of having taken a course and subjective knowledge do no predict the acceptance of GT; only the interest variable has a significant effect on acceptance at $5 \%$ level of significance. However, the gender variable with only a P-value of 0.069 has a significant effect on the acceptance at $10 \%$ level of significance. The second level of the risk variable also has a significant effect on acceptance at $10 \%$ level of significance.

Under these circumstances, the course and knowledge variables were removed from the complete full model and the binary logistic regression was carried out once again.

The variables of having taken a course and subjective knowledge do no predict the acceptance of GT; only the interest variable has a significant effect on acceptance at $5 \%$ level of significance. However, the gender variable with only a P-value of 0.069 has a significant effect on the acceptance at $10 \%$ level 
of significance. The second level of the risk variable also has a significant effect on acceptance at $10 \%$ level of significance.

Under these circumstances, the course and knowledge variables were removed from the complete full model and the binary logistic regression was carried out once again.

It can be said at $90 \%$ level of confidence that the gender has a significant effect on the acceptance. It can be said at $95 \%$ level of confidence that all levels of the interest variable and only last level of the risk varible have significant effect on the acceptance statistically. The effect of the risk variable is not regarded as significant generally $(\mathrm{P}=0,101)$. This may stem from not regarding the first level of this variable as significant. Rate of right classification of the reduced model is $60,9 \%$ for those not accepting and $81,7 \%$ for those accepting General rate of right classification is $71,9 \%$. Nagelkerke $\mathrm{R}^{2}$ value of this model is 0,32 . The rates of right classification received for this model and Nagelkerke $\mathrm{R}^{2}$ value are at acceptable level. The gender was removed from the model due to the fact that it is not significant at 95\% confidence level and the following model was introduced. In the last model, acceptance situation was explained through the interest and risk.

According to the Wald test results (Table 1), there has been a significant increase in the risk variable's significance with the removal of gender. Except for the first category of the risk variable, all parameters are significant at $5 \%$ level of significance. The risk variable is significant in general at $10 \%$ level of significance. The model generated according to the last model's percentage of correct classification correctly predicts those that do not accept as $54.7 \%$ and those that accept as $87.3 \%$. The general percentage of the correct classification is once again $71.9 \%$. The Nagelkerke $\mathrm{R}^{2}$ value of the last model is 0.29 . The decrease in the Nagelkerke $R^{2}$ value is mainly due to the removal of variables from the model. The state of acceptance through interest and risk is $29 \%$. The correct predict being around $72 \%$ makes the Nagelkerke $\mathrm{R}^{2}$ value achieved from the last model to be acceptable at a good rate.

Table 1. Significance tests of the last model's parameters

\begin{tabular}{llll}
\hline Parameter & Wald & df & P-value \\
\hline Interest & 21.976 & 2 & 0.000 \\
Interest (Average) & 8.662 & 1 & 0.003 \\
Interest (High) & 21.459 & 1 & 0.000 \\
Risk & 5.676 & 2 & 0.059 \\
Risk (Low) & .020 & 1 & 0.888 \\
Risk (Average) & 4.346 & 1 & 0.037 \\
Fixed & 10.269 & 1 & 0.001 \\
\hline df: degree of freedom & &
\end{tabular}

To survey the influence of an increase or a decrease in the levels of variables predicting the acceptance perception of GT on acceptance perception, by taking the low interest level in the interest variable and the high risk level in the risk variable as the reference level while analyzing the last model, its parameter predicts, odds ratios, and their 95\% confidence intervals are given in Table 2 .

Table 2. Last model's parameter predicts, odds ratios, and their level of significance

\begin{tabular}{|c|c|c|c|c|c|}
\hline & \multirow[b]{2}{*}{ B } & \multirow[b]{2}{*}{ SE } & \multirow[b]{2}{*}{$\operatorname{Exp}(B)$} & \multicolumn{2}{|c|}{ 95\% Confidence Interval } \\
\hline & & & & LB & UB \\
\hline Interest & & & & & \\
\hline Interest (Average) & -1.387 & 0.540 & 0.250 & 0.087 & 0.720 \\
\hline Interest (High) & 1.364 & 0.464 & 3.913 & 1.577 & 9.709 \\
\hline
\end{tabular}




\begin{tabular}{lccccc} 
Risk (Low) & 0.066 & 0.466 & 1.068 & 0.428 & 2.662 \\
Risk (Average) & -1.077 & 0.517 & 0.341 & 0.124 & 0.938 \\
Fixed & 0.167 & 0.338 & 1.182 & & \\
\hline
\end{tabular}

B: Parameter Predict; SE: Standard Error; LB: Lower Bound; UB: Upper Bound.

According to the Exp (B) column of Table 2, when the effect of risk is fixed, Acceptance is 0.250 times more in average interesteds than low interesteds and it is 3.9 times more in highly interesteds than low interesteds. This shows the fact that as the person's interest in GT increases he accepts even more. When the effect of the interest is fixed, acceptance is 1.1 times more in low risk than high risk and 0.341 times more in average risk than high risk. As the finding risky level increases, less people accept.

As a conclusion, according to the binary logistic regression analysis carried out, the interest and risk variables are variables predicting acceptance regarding GT. Having taken courses on GT and subjective knowledge predictions towards GT do not provide explanation to the interest perception regarding GT. The gender variable can be said to have a significant effect on acceptance but at $10 \%$ level of significance. Moreover, according to the results of this study, when perception regarding GT to be risky decreases and interest towards GT increases, the acceptance perceptions regarding GT by biology teachers increases.

\section{Discussion}

According to the binary logistic regression analysis (Tables 1 and 2), 29\% of the variables, which are significantly effective at $5 \%$ level of significance, predict the interest and risk variables' acceptance of GT. Having taken courses related to GT and carrying out subjective knowledge predictions towards GT does not predict its acceptance perception. The gender variable is significantly effective on acceptance however only at $10 \%$ level of significance. In addition, by the model generated in this study, it is possible to state a good rate, $72 \%$, of people approving GT (Table 1). Moreover, according to the results of this study, when perception regarding GT being risky decreases and interest towards GT increases, the acceptance perceptions regarding GT by biology teachers increases (Table 2).

Interest towards GT, according to our study, is an important element predicting acceptance of this technology (Table 1). Urban and Pfenning (1999) inform that interest enables people to pay attention to the information sources, to consider and to evaluate the received information, and to be motivated and willing to gather detailed information about the subject. According to Cacioppo and Petty (1985), depending on a person's range of personal interests of a subject, they form behavior towards the object (Elpeze-Ergeç, 2004). A person's interest with the subject increases his motivation and personal interest affects thoughts (Petty and Cacioppo 1986). According to Petty and Cacioppo (1979), for a more active information-processing course, high interest is used as an important medium of motivation (Petty et al., 2002). As for Petty, Brinol, and Tormala (2002), if personal interest is high, the person will look into the subject much more and will shape his attitude according to his deductions. In other words, the increase of personal interest increases consideration on knowledge. According to the outcomes of our study, the risk evaluation carried out on GT is another important element to predict acceptance of GT (Table 1). Some studies also state risk perception as a predictive element in approving GT (Saba et al., 2000; Siegrist, 2000). According to the Elaboration Likelihood Model of Petty and Cacioppo, who state that the attitude towards the object is a product of thought and accumulation, people are interested in the experience and accumulation they have on the subject, they carefully review it, and if they try to understand it they form an interpretation. In other words, by carrying out their evaluations they gain knowledge and develop an attitude (Elpeze-Ergeç, 2004; Kağıtçıbaşı, 2005). In this case, those who have experience and accumulation on the risks and disadvantages of GT will want to gain knowledge on GT, evaluate and process the information 
actively by revising their experiences, and clarify their decisions and attitude towards product/applications of GT. The presence of a somewhat relation between the average levels of interest and knowledge and results of our logistic regression (Tables 1 and 2) support these comments.

According to another outcome of our study, although individuals approving GT is at stake, having taken a course, formal information, on GT and considering oneself to be knowledgeable does not describe the acceptance of GT. Because people actively process information, Petty and Cacioppo (1981) inform that although reaction is actively given to information, the effect of acceptance on the object is that significant. According to this approach, easily understanding, that is learning or knowing, information is related to acceptance very less (Elpeze-Ergeç, 2004). It can be said that the attitude may change when the message is not understood (Kağıtçıbaşı, 2005). In fact, according to some researchers, educational background and knowledge level are not strong descriptives of opinion, acceptance, and attitude regarding GT (Frewer et al., 1997; Jallinoja and Aros, 2000; HornigPriest et al., 2003; Connor and Siegrist, 2010).

The gender variable, according to our study, has a significant effect on the acceptance of GT (Tab. 1). Siegrist (2000) as well informs that gender makes a difference regarding acceptance and that women accept GT less than men do; Magnusson and Hursti (2002), in addition, state that men consider GT more positively than women.

When the perception of GT being risky decreases and interest in GT increases, the prospective teachers' acceptance perception increasing is another outcome of this study (Tab. 2). Accordingly, it is suggested that considering GT being less risky and being interested with it highly shape behavior and evaluation towards approving GT. This is worth the attention in terms of performing valid predictions regarding which behavior prospective teachers and individuals would prefer when including GT related products and applications, which decisions they would make, and in which direction they would carry out their preference and evaluation. According to our study, it is predicted from the logistic regression model that a person with high interest level and average risk level has 0.61 possibility of approving GT; whereas a person with high interest level and low risk level has 0.82 possibility of approving GT. From this point, it can be understood that a decrease in level of risk perception has a significant influence (this increases the possibility $34 \%$ ) on the possibility of approving GT.

\section{Conclusions and Implications}

Our results are suggested that considering GT being less risky and being interested with it highly shape behavior and evaluation towards approving GT. According to our study, it is predicted from the logistic regression model that it can be understood that a decrease in level of risk perception has a significant influence on the possibility of approving GT. Studying the learning environment that effects the formation of individuals' knowledge and opinions regarding GT will show domain the school's biology education possesses. When the influence of the information and attitudes the biology teachers transfer into their students is considered, and as GT product and applications develop, it is obvious that the contribution and efficiency of schools and biology teachers on opinion formation will be discussed. Accordingly, school and education life should be dynamized at carrying out conscious evaluations on matters, such as GT, that are related with our future; more studies focusing on the formation of teachers' opinions and qualifications of biology teacher education and training programmes should be carried out. In addition to the variables such as gaining knowledge, gender, and risk, variables such as interest, expectation, and necessities that influence motivation can also be suggested to be studied in detail through different sample types and sizes when considering the place 
and contributions of high technologies, such as GT, that are implemented to our lives through planning.

\section{Acknowledgements}

We would like to thank Necdet Sağlam, Esin Atav, Banu Şebnem Önder for their support and contributions throughout this study.

\section{References}

Bergan, J. R., (1983). Latent-class models in educational research. Review of Research in Education, 10, 305-360.

Bonfadelli, H., Dahinden, U. and Leonarz, M., (2002). Biotechnology in Switzerland: High on the public agenda, but only moderate support. Public Understanding of Science, 11, 113-130.

Brown, T.A., (2002). Gentechnology für Einsteiger. Spektrum Akademischer Verlag, Heidelberg, Berlin.

Cabrera, A.F., (1994.) Logistic regression analysis in higher education: An applied perspective. Higher Education: Handbook of Theory and Research. 10, 225-256.

Connor, M. and Siegrist, M., (2010). Factors influencing people's acceptance of gene technology: the role of knowledge, health expectations, naturalness, and social trust. Science Communication, 32, no. 4: 514-538, DOI: 10.1177/1075547009358919

Costa-Font, M., Gil, J.M. and Traill, W.B., (2008). Consumer acceptance, valuation of and attitudes towards genetically modified food: Review and implications for food policy. Food Policy, 33, 99-111.

Dawson, V. and Schibeci, R. (2003)., Western Australian school students' understanding of biotechnology. International Journal of Science Education, 25(1), 57-69

Demirhan, H., (2011) Latent class analysis for models with error of measurement using log-linear models and an application to women's liberation data, Journal of Data Science, 9, 43-54

Elpeze-Ergeç N., (2004). Televizyon Reklamlarına Yönelik Şüphe. Anadolu Üniversitesi Yayınları No: 1553, İletişim Bilimleri Fakültesi Yayınları No: 57

Frewer, L.J., Howard, C. and Shepherd, R., (1997). Public concerns in the United Kingdom about general and specific applications of genetic engineering: Risk, benefit, and ethics. Science, Technology, and Human Values, 22: 98-124.

Gaskell, G., Bauer, M. W. and Durant, J. (1998). The Presentation Of Biotechnology: Policy, Media And Public Perception. In Durant, J., Bauer M. W. and Gaskell, G. eds., Biotechnology in the Public Sphere: a European Source Book. NMSI Trading Ltd., Science Museum, London, ISBN: 190074709 X.

Gaskell, G. and Bauer, M.W., (2001). Biotechnology in the Years of Controversy: A Social Scientific perspective. In Gaskell, G. and Bauer M.W. eds. Biotechnology 1996-2000 the Years of Controversy. NMSI Trading Ltd., Science Museum, London, ISBN: $120074743 X$.

Harman, A. and Akın, M.F., (2006). Assessment on the students of the faculty of education in terms of the method of mathematics teaching. Electronic Journal of Social Sciences (Fall, 18) [Online]: Retrieved on 27-July-2007, at URL: http://www.e-sosder.com ISSN:1304-0278 Fall -2006 C.5 18,124-130.

Harms, U. and Bayrhuber, H., (1999). Biotechnologie im Unterricht, Biotechnologie und Gentechnik. In M. Schallies, und K.D. Wachlin eds. Biotechnologie und Gentechnik, Springer Verlag Berlin, Heidelberg, Newyork, 87-98.

Harms, U., (2002). Biotechnology Education in schools. Electronic Journal of Biotechnology, 5(3). http://www.ejbiotechnology.info /content/vol5/issue3/teaching/01/ (accessed August 2004)

Heinen, T., (1996). Latent Class and Discrete Latent Trait Models: Similarities and Differences, Sage, Thousand Oaks.

Hornig-Priest, S., Bonfadelli, H. and Rusanen, M., (2003). The "trust gap" hypothesis: predicting support for biotechnology across national cultures as a function of trust in actors. Risk Analysis, 23(4), 751-766, DOI:10.1111/1539-6924.00353.

Hosmer, D.W. and Lemeshow, Jr. S., (2000). Applied Logistic Regression. 2nd Ed., Wiley, New York.

Hsieh, F.Y., Bloch, D.A. and Larsen, M.D., (1998). A simple method of sample size calculation for linear and logistic regression. Statistics in Medicine, 17, 1623-1634.

Hursti, U.K., Magnusson, M.K. and Algers, A., (2002). Swedish consumers' opinions about Gene Technology. British Food Journal, 104(11), 860-872.

Jallinoja P. and Aros, A.R., (2000). Does knowledge make a difference? The association between knowledge about genes and attitudes toward gene test. Journal of Health Communication, 5(1), 29-3

Kağıtç̧başı, Ç., (2005). Yeni İnsan ve İnsanlar. Evrim Yayınevi, İstanbul, 101.

Knox, B., (2000). Consumer perception and understanding of risk from food. British Medical Bulletin, 56(1), 97-109

Linzer, D.A. and Lewis, J.B., (2011). An $\{$ R $\}$ Package for polytomous variable latent class analysis. Journal of Statistical Software, $42,1-29$.

Magnusson K.M. and Hursti, U.K., (2002). Consumer attitudes towards genetically modified foods. Appetite 39, 9-24.

Menard, S.W., (1995). Applied Logistic Regression Analysis. Sage Publications, Thousand Oaks.

Merten, K. (1999). Die Berichterstattung über Gentechnik in Presse und Fernsehen- eine Inhaltsanalyse. In J. Hampel and O. Renn, eds. Gentechnik in der Öffentlichkeit, Campus Verlag, Frankfurt/Main; Newyork, ISBN 3-593-36348-8, 317-339.

Nylund, K.L., Asparouhov, T. and Muthen, B.O., (2007). Deciding on the number of classes in latent class analysis and growth mixture modeling: a monte carlo simulation study. Structural Equation Modeling, 14, 535-569. 
Peters H.P., (1999). Kognitive Aktivitaeten bei der Rezeption von Medienberichten über Gentechnik. In J. Hampel and O. Renn eds. Gentechnik in der Öffentlichkeit, Frankfurt/Main; Newyork: Campus Verlag, ISBN 3-593-36348-8, 340-382.

Petty, R.E. and Cacioppo, J.T., (1986). The Elaboration Likelihood Model of Persuasion. In L. Berkowitz eds. Advances in experimental social psychology, San Diego, CA: Academic Pres, 19, 123-205.

Petty, R.E., Brinol, P. and Tormala, Z.L., (2002). Thought confidence as a determinant of persuasion: the self-validation hypothesis. Journal of Personality and Social Psychology, 82(5), 722-741.

Pfister H.R., Böhm, G. and Jungermann, H., (2000). The cognitive representation of genetic engineering: Knowledge and evaluations. New Genetics and Society, Special Issue, 19(3), 295-316.

Saba, A., Rosati, S. and Vassallo, M., (2000). Biotechnology in agriculture: perceived risks, benefits and attitudes in Italy. British Food Journal, 102(2), 114-121.

Siegrist, M. (2000). The Influence of Trust and perceptions of risks and benefits on the acceptance of GT. Risk Analysis, 20(2), 195-203.

Todt, E. and Götz, C., (1997). Hoffnungen und Befürchtungen von jugendlichen gegenüber der Gentechnik. Zeitschrift für Didaktik der Naturwissenschaften, 3(2), 15-22.

Todt, E. and Götz, C., (1998). Interesse von jugendlichen an der Gentechnologie. Zeitschrift für Didaktik der Naturwissenschaften, $4(1),: 3-11$.

Urban, D. and Pfenning, U., (1999). Technikfurcht und Technikhoffnung. Verlag Grauer, Stuttgart, ISBN 3-86186-278-6. 